\title{
11
}

\section{The environmental consequences of foreign direct investment in China}

\author{
Qun Bao, Yuanyuan Chen and Ligang Song
}

China has been the largest recipient of foreign direct investment (FDI) in the developing world since 1990, and there has been a profound change in China's foreign investment policy in the past decade. It is acknowledged generally that FDI has played a significant role in promoting China's rapid economic growth through meeting the gaps of capital shortage, pushing technology spill-over towards local firms and improving the degree of China's economic openness (Cheung and Lin 2004; Yao 2006). Foreign direct investment has, however, also had some negative impacts on China's economy, which have increasingly aroused concern. Among them, the environmental consequences of the entry of foreign firms have attracted much attention: FDI could be a contributing factor to the serious environmental damage that has accompanied China's rapid economic growth. Questions can be asked about whether further increases in FDI will intensify pressure for environmental protection in China. While foreign investments in pollution-intensive industries, including mining, have accounted for a large share of China's total FDI, ${ }^{1}$ does foreign investment cause more pollution emissions and therefore environmental damage, as is the fear of most people in China?

One of the most popular viewpoints about the effect of economic openness on environmental quality is the 'pollution haven hypothesis' $(\mathrm{PHH})$, which supposes that developing countries in general have comparative advantages in polluting sectors due to their relatively lax environmental regulation. As a result, by relocating pollution-intensive industries from richer countries to poor countries through either international trade or FDI, multinational firms can 
achieve lower production costs in the host country. A corollary is the 'race to the bottom' phenomenon - that is, in order to attract more foreign investment, developing countries might deliberately undervalue their environmental damage, and lower their environmental standards. A number of empirical studies have examined the relationship between foreign investment and local environmental pollution in host countries; however, their estimation results are generally mixed. Two possible reasons could explain why tests on the pollution haven hypotheses have so far not been able to provide conclusive results. The first is that econometric results could suffer from omitted variables and model specification as well as from the pollution-emission indicators the authors have chosen. Second, while foreign firms might cause increased pollution emissions in host countries, they also help to reduce local pollution emissions by adopting cleaner technology and through the productivity spill-over effect. As a result, the effect of foreign investment on local environmental quality could be ambiguous, which implies that the relationship between FDI and pollution emissions could be non-linear.

Since a linear relationship has generally been assumed in most previous studies, few researchers have examined the possible non-linear impact of foreign investment on local environmental pollution. In this chapter, we attempt to check empirically whether there is such a non-linear effect of FDI on pollution in host countries, by using China's panel data of provinces. The remainder of this chapter is organised as follows: the next section provides a review of the literature and the motivation for our research. Section three introduces the model specification and data descriptions. Section four presents our empirical results, and section five provides the conclusion.

\section{Literature review}

A number of econometric studies have examined whether differences in environmental standards among host countries can act as determinants of the location of foreign investment, and three approaches have been used (Dean et al. 2004). ${ }^{2}$ The first approach is a cross-country data study. For example, in their study on the location choice of multinational firms across Eastern Europe and the former Soviet Union, Smarzynska and Wei (2001) consider the roles played by corruption and environmental regulation, and their estimation results do not support the idea that lower environmental standards lead to increased foreign investment. The second approach is an inter-state data study, which investigates mainly whether environmental stringency affects the location decisions of firms across the United States (for example, Levinson 1996; Keller and Levinson 2002; List et al. 2004; Henderson and Millimet 2007). The third 
approach is an inter-industry data study. For example, Eskeland and Harrison (2003) examine the location decisions of foreign firms across different industries within countries, including Mexico and Morocco. Similar to Smarzynska and Wei (2001), the authors find that abatement costs are not a significant variable in determining the location of foreign firms among manufacturing industries within one country. Additionally, Eskeland and Harrison (2003) found that foreign ownership was related significantly to lower pollution intensity.

What should be mentioned is that empirical work designed to test the pollution haven hypothesis has so far not been able to provide conclusive results, ${ }^{3}$ which could be explained by two factors. First, the econometric results could suffer from the problems of omitted variables, model specification and measurement errors (Letchumanan and Kodama 2000). As well as these problems, the estimated effects of foreign investment on environmental quality in a host country are likely to be influenced by the pollutant indicator proxies adopted. Second, it has also been proposed that foreign investment could help improve local environmental quality in host countries. For example, since multinational firms apply a universal environmental standard, they tend to diffuse their clean technology among their local counterparts in the host country, which generates the 'pollution halo hypothesis' (Birdsall and Wheeler 1993; Chudnovsky and Lopez 1999). Additionally, foreign investment could cause technological spill-overs to the local firms, crowding out inefficient local firms and improving the efficiency of energy and resource usage, which helps to decrease local pollution emissions (Wayne and Shadbegian 2002; Liang 2006).

The impacts of the entry of foreign firms on China's environmental quality and pollution emissions have also been studied. For example, by using the data from about 1,000 industrial firms in three Chinese provinces, Wang and Jin (2002) explore the differences in the pollution control performance of industries with different types of ownership. They find that foreign-owned and collectively owned enterprises have the best environmental performance in terms of water pollution discharge intensity, while state-owned enterprises and privately owned enterprises in China are the worst performers. To explain their findings, Wang and Jin suggest that foreign-owned enterprises might adopt more environmentally friendly technology in their production than other firms. Similarly, based on data from China's 260 cities, Liang (2006) also shows that the entry of foreign investment doesn't harm environmental quality in China, since a negative relationship is found between FDI and air pollution. Specifically, a 1 per cent increase in FDI will decrease sulphur dioxide emission intensity by $0.6-0.7$ per cent, according to Liang (2006). A simultaneous estimation 
technique has been applied in He (2002) to decompose the impact of FDI on sulphur dioxide emissions into the scale, technique and composition effects. By using China's city-level panel data from 1993-99, He (2002) reached a similar conclusion: that the entry of FDI helped reduce sulphur dioxide emissions. Additionally, others considered the role of industrial composition and sources of foreign investment. For example, Dean et al. (2004) find that the environmental consequence of FDI varies with its sources. While FDI originating from Hong Kong, Taiwan and Macao is attracted to provinces with weak environmental controls, FDI from non-Chinese sources is attracted to areas with higher levels of skilled labour and high pollution levies.

\section{Table 11.1 Selected literature on the relationship between FDI and pollution}

\begin{tabular}{|c|c|c|c|}
\hline Authors & Sample data & Pollutant proxies & Conclusions \\
\hline $\begin{array}{l}\text { Eskeland and } \\
\text { Harrison (2003) }\end{array}$ & $\begin{array}{l}\text { US outward investment } \\
\text { in four countries, } \\
\text { including Mexico and } \\
\text { Morocco }\end{array}$ & $\begin{array}{l}\text { Various proxies, } \\
\text { including air and } \\
\text { water pollution }\end{array}$ & $\begin{array}{l}+ \text { (compared } \\
\text { with local firms) }\end{array}$ \\
\hline $\begin{array}{l}\text { Smarzynska and } \\
\text { Wei (2001) }\end{array}$ & $\begin{array}{l}\text { Foreign investments } \\
\text { across } 25 \text { transitional } \\
\text { economies }\end{array}$ & $\begin{array}{l}\text { Inventory of toxins } \\
\text { released }\end{array}$ & - \\
\hline $\begin{array}{l}\text { Wang and Jin } \\
(2002)\end{array}$ & $\begin{array}{l}\text { Data from more than } \\
1,000 \text { firms in China }\end{array}$ & $\begin{array}{l}\text { SO2, suspended } \\
\text { particulate matter }\end{array}$ & $\begin{array}{l}\text { + (compared } \\
\text { with state-owned } \\
\text { enterprises and } \\
\text { private enterprises) }\end{array}$ \\
\hline Dean et al. (2004) & $\begin{array}{l}2,886 \text { manufacturing } \\
\text { joint-venture projects } \\
\text { during } 1993-96 \text { in China }\end{array}$ & Water pollution & $\begin{array}{l}\text { Foreign investment } \\
\text { sources do matter }\end{array}$ \\
\hline $\mathrm{He}(2002)$ & $\begin{array}{l}\text { China's city-level panel } \\
\text { data from 1993-99 }\end{array}$ & $\mathrm{SO} 2$ & + \\
\hline Liang (2006) & $\begin{array}{l}\text { Data from China's } \\
260 \text { cities }\end{array}$ & $\mathrm{SO} 2$ & + \\
\hline
\end{tabular}

Note: The '+' sign denotes that foreign investments helped improve local environmental quality in host countries.

Source: Authors' own summary. 
Since a linear relationship between FDI and pollution emissions has generally been assumed in these studies, few have considered a non-linear possibility - as far as we know. Could the environmental impact of FDI be nonlinear? There are two main motivations for our research. First, the logic of the non-linear FDI-pollution nexus is very similar to the well-known environmental Kuznets curve (EKC) hypothesis, which states that the relationship between economic growth and pollution emissions could follow an inverted-U curvenamely, environmental degradation worsens in the early stages of growth, but eventually reaches a peak and starts declining as incomes exceed a certain threshold. ${ }^{4}$ The logic of an EKC relationship is intuitively appealing. In the first stage of industrialisation, pollution grows rapidly because high priority is given to increasing material output, and people are more interested in increasing jobs and incomes than having clean air and water (Dasgupta et al. 2002). The rapid growth results inevitably in greater use of natural resources and increased emissions of pollutants, which in turn put more pressure on the environment. People are too poor to pay for abatement and disregard the environmental consequences of growth. In the late stage of industrialisation, as incomes rise, people value the environment more, the regulatory institutions become more effective and, as a consequence, pollution levels decline. The EKC hypothesis therefore posits a well-defined relationship between the level of economic activity and environmental pressure (defined as the level of concentration of pollution or flow of emissions, depletion of resources and so on). Such an inverted-U curve relationship could naturally extend to the FDI-pollution nexus: in the initial stage of FDI utilisation, the entry of multinational firms leads to a higher scale of production activities in host countries. Meanwhile, people in the poor host country have low demands for a clean environment, as the pollution damage is trivial, so fewer resources will be allocated to abate environmental pollution. As a result, foreign investment causes pollution emissions in host countries to rise; however, as the income levels of the host country's residents increase steadily with the accumulation of foreign investment, people become less tolerant of declining environmental quality, propelling the government to implement more stringent environmental regulations, and, therefore, more pollution abatement endeavours will be undertaken. Meanwhile, as foreign firms adopt more environmentally friendly techniques, the entry of FDI can cause a spill-over effect of clean technology to local firms, which eventually affects the industrial structure in host countries. As a result, once a certain threshold has been passed, foreign investment will be beneficial to local environmental quality. ${ }^{5}$ 
Second, concerning the relationship between FDI and pollution in China, it is hard to provide strong evidence to support the linear assumption. Although it has been found (Wang and Jin 2002; He 2002; Liang 2006) that foreign investment generally helps to reduce China's pollution emissions, the environmental effect of FDI varies significantly between different regions in China, as shown in Table 11.2. While the eastern region has accounted for a much larger share of FDI than other regions in the past due to its geographical location and its infrastructure facility advantage, provinces in the eastern region have not performed much better than those in other regions in terms of environmental protection. For example, Guangdong ranks the highest in terms of attracting FDI, with the largest average share of 27.5 per cent. Its pollution behaviour is, however, very similar to Hubei, Hunan and Guizhou, all of which are in central or western China. Emission levels of four pollution indicators in Guangdong, including 'water', 'cod' (chemical oxygen demand), 'smoke' and 'solid', have a mean value similar to those in Hubei; however, the mean value of FDI in Hubei is less than one-tenth of that in Guangdong. Additionally, even within the eastern region, the performance of individual provinces varies. For instance, during 1992-2004, the emission levels of three pollutants, excluding cod, showed an increasing trend in Guangdong, which implies that it emits more pollution to the local environment than other eastern provinces. In comparison, Shanghai behaves much better than Guangdong, as its emission levels of the four pollutants all decline, except solid. Such casual observation demonstrates that, in terms of local environmental quality, while some provinces benefit from the entry of foreign firms, others lose. In other words, the potential relationship between FDI and the local environment could be non-linear rather than the linear one assumed previously.

\section{Model specification and data description}

To examine the non-linear impact of foreign investment on China's pollution emissions, we use China's panel data from 29 provinces during 1992-2004. Tibet is excluded from the sample due to the unavailability of data for certain indicators. Chongqing became a municipality only in 1997, so we integrate its data into that for Sichuan Province as a whole. Our estimation model is set as follows.

$$
P_{i t}=c_{i}+\gamma_{t}+\alpha_{1} f d i_{i t}+\alpha_{2} f d i_{i t}{ }^{2}+\alpha_{3} \text { scale }_{i t}+\alpha_{4} \operatorname{comp}_{i t}+\alpha_{5} t e c h_{i t}+\beta C V_{i t}+\varepsilon_{i t}
$$

in which $P_{i t}$ denotes various pollutant emissions in province $i$ for year $t$; $f d i_{i t}$ denotes FDI in province $i$ for year $t$; $c_{i}$ and $\gamma_{t}$ denote regional and time-specific 
Table 11.2 FDI and pollution emissions among different provinces

\begin{tabular}{|c|c|c|c|c|c|c|}
\hline & $F D I$ & cod & smoke & gas & water & solid \\
\hline & US $\$ 100$ & $(10$ & $(10$ & $(10$ & $(100$ & $(100$ \\
\hline & million & million kg) & million kg) & million kg) & billion kg) & billion kg) \\
\hline Guangdong & 113.76 & $29.51(-12)$ & $23.63(2.4)$ & $72.96(61.51)$ & $12.89(2.27)$ & $0.17(0.08)$ \\
\hline Jiangsu & 61.73 & $35.01(-13.43)$ & $46.03(-14)$ & $112.92(-1.46)$ & $22.38(3.86)$ & $0.31(0.22)$ \\
\hline Shanghai & 37.77 & $10.02(-15.84)$ & $10.24(-9.56)$ & $38.82(-16.41)$ & $9.29(-8.06)$ & $0.13(0.06)$ \\
\hline Shandong & 34.73 & $68.79(-28.03)$ & $55.13(-6.6)$ & $174.73(-71.28)$ & $10.42(4.22)$ & $0.53(0.39)$ \\
\hline Fujian & 34.25 & $14.67(-9.81)$ & $8.24(3.00)$ & 18.55 (16.93) & $6.79(5.18)$ & $0.19(0.26)$ \\
\hline Liaoning & 22.44 & $29.66(-23.82)$ & $56.54(-33.1)$ & $81.38(-42.48)$ & $11.96(-6.12)$ & $0.75(0.08)$ \\
\hline Zhejiang & 20.86 & $29.12(-6.55)$ & $20.27(2.80)$ & $56.80(27.71)$ & $12.45(4.86)$ & $0.13(0.13)$ \\
\hline Beijing & 16.21 & $4.79(-9.07)$ & $7.65(-7.7)$ & $22.16(-24.38)$ & $2.90(-2.70)$ & $0.11(0.04)$ \\
\hline Tianjin & 15.70 & $6.29(-5.74)$ & $8.12(-0.40)$ & $22.18(-2.88)$ & $2.04(0.15)$ & $0.05(0.03)$ \\
\hline Hubei & 10.72 & $27.77(-19.8)$ & $24.86(4.40)$ & 49.38 (11.95) & $11.95(4.71)$ & $0.24(0.13)$ \\
\hline Hebei & 7.76 & 36.18 (11.78) & $54.12(8.60)$ & $109.27(28.56)$ & $9.53(3.73)$ & $0.77(1.11)$ \\
\hline Hunan & 7.47 & $31.43(-12.4)$ & 33.97 (17.5) & 57.67 (21.86) & $13.41(-5.52)$ & $0.22(0.12)$ \\
\hline Hainan & 6.27 & $3.30(-5.32)$ & $1.39(-0.10)$ & $2.21(-0.26)$ & $0.76(-0.34)$ & $0.01(-0.00)$ \\
\hline Jiangxi & 6.11 & $11.95(-13.11)$ & $21.72(-8.50)$ & $31.86(15.23)$ & $5.51(-1.97)$ & $0.44(0.31)$ \\
\hline Guangxi & 6.10 & $56.85(27.14)$ & $36.82(25.00)$ & $66.91(28.02)$ & $9.37(2.89)$ & $0.20(0.19)$ \\
\hline Henan & 5.02 & $45.06(-5.76)$ & $52.33(27.70)$ & $71.50(53.55)$ & $10.10(2.23)$ & $0.33(0.29)$ \\
\hline Sichuan & 4.82 & 49.32 (7.29) & $73.23(20.50)$ & $153.40(6.25)$ & $17.90(0.32)$ & $0.49(0.31)$ \\
\hline Heilongjiang & 4.14 & $19.56(-15.23)$ & $43.63(-11.9)$ & $26.41(-2.48)$ & $6.04(-3.22)$ & $0.31(-0.06)$ \\
\hline Anhui & 3.69 & $22.15(-25.8)$ & $23.74(-3.5)$ & $38.74(1.82)$ & $7.30(-3.32)$ & $0.29(0.12)$ \\
\hline Jilin & 3.16 & $20.69(-14.13)$ & $29.63(-3.3)$ & $22.32(-1.87)$ & $3.94(-1.18)$ & $0.16(0.05)$ \\
\hline Shaanxi & 3.03 & $11.03(6.68)$ & $35.21(-2.9)$ & 63.57 (3.79) & $3.40(-0.14)$ & $0.23(0.22)$ \\
\hline Shanxi & 1.82 & $16.98(-21.67)$ & $64.72(49.4)$ & $94.27(35.05)$ & $3.76(-0.91)$ & $0.61(0.62)$ \\
\hline Neimenggu & 1.26 & $17.04(5.24)$ & $40.40(-48.40)$ & $66.78(29.61)$ & $2.46(-0.41)$ & $0.27(0.26)$ \\
\hline Yunan & 1.06 & $19.56(-7.35)$ & $17.93(-1.20)$ & $31.31(15.07)$ & $3.97(-0.56)$ & $0.26(0.22)$ \\
\hline Xinjiang & 0.75 & $12.46(5.83)$ & $12.80(0.10)$ & $23.01(7.95)$ & $1.73(-0.09)$ & $0.07(0.07)$ \\
\hline Guizhou & 0.69 & $5.26(-2.99)$ & $27.37(-5.70)$ & $66.04(-11.50)$ & $2.40(-1.28)$ & $0.22(0.32)$ \\
\hline Gansu & 0.61 & $5.06(-2.40)$ & $14.57(-1.30)$ & 36.21 (8.35) & $2.98(-1.92)$ & $0.15(0.09)$ \\
\hline Qinghai & 0.52 & $0.40(-0.34)$ & $4.60(2.10)$ & $2.87(4.30)$ & $0.45(-0.18)$ & $0.03(0.02)$ \\
\hline Ningxia & 0.25 & $6.57(2.33)$ & $9.93(-2.40)$ & $20.63(4.23)$ & $0.92(0.16)$ & $0.04(0.02)$ \\
\hline
\end{tabular}

Note: We list the mean value of each indicator during 1992-2004, and the values in parentheses are the emission levels in 2004 minus those in 1992 for each pollutant-measuring the change in pollution emissions. water is industrial polluted water; solid is industrial solid wastes; cod is chemical oxygen demand in industrial water pollution; gas is sulphur dioxide emissions; smoke is industrial smoke.

Source: Authors' own calculations, using pollution emissions data from various issues of State Environmental Protection Administration (SEPA), various years. China Environment Yearbook, China Environment Yearbook Press; and FDI data from National Bureau of Statistics (NBS), various years. China Statistical Yearbook, China Statistics Press, Beijing. 
effects respectively; $\varepsilon_{i t}$ is a normally distributed error term. What should be mentioned here is that we include $f d i_{i t}$ and $f d i_{i t}{ }^{2}$ in our estimation model: if the coefficient of $f d i_{i t}{ }^{2}$ is estimated as zero, $\alpha_{2}=0$, then only a linear relationship exists between foreign investment and pollution emissions. If $\alpha_{2}<0$, it implies that there is an inverted-U curve relationship between $f d i$ and pollution emissions, while a positive $\alpha_{2}$ indicates a $U$-shape relationship. In the meantime, we can further calculate the turning-point along the inverted-U curve by taking the first-order differentiation of the empirical model as:

$$
f d i^{*}=-\frac{\alpha_{1}}{2 \alpha_{2}}
$$

Similar to Grossman and Krueger (1995) and Antweiler et al. (2001), the indicators scale, comp and tech measure the scale effect, composition effect and technique effect respectively, while $C V$ represents other variables that could affect the level of pollution emissions.

We choose the indicators and provide our data description as follows.

Five pollutant indicators are chosen in this study to measure different pollution emissions - two water pollutants (industrial polluted water emissions and chemical oxygen demand in industrial water pollution), two air pollutants (industrial smoke emissions and sulphur dioxide emissions) and one solid pollutant (industrial solid wastes)—from 1992 to 2004 in 29 of China's provinces and municipalities. Table 11.3 lists the description of all the pollutant variables and our data sources. We chose five different pollutant indicators because we could not compare only the impacts of foreign investment on different

\section{Table 11.3 Five indicators of pollution emissions in China}

\begin{tabular}{|c|c|c|}
\hline Pollutant & Unit & Symbol \\
\hline 1 Industrial polluted water emissions & 100 billion $\mathrm{kg}$ & water \\
\hline Chemical oxygen demand in industrial water pollution & 10 million $\mathrm{kg}$ & cod \\
\hline Sulphur dioxide emissions & 10 million $\mathrm{kg}$ & gas \\
\hline Industrial smoke emissions & 10 million $\mathrm{kg}$ & smoke \\
\hline Industrial solid wastes & 100 billion $\mathrm{kg}$ & solid \\
\hline
\end{tabular}

Sources: State Environmental Protection Administration (SEPA), 1993-2005. China Environment Yearbook, China Environment Yearbook Press, Beijing. 
pollutants; rather, we needed to also ensure the robustness of our estimated inverted-U curve. Our original pollutant data from 1992-97 were collected by dividing all industries into 18 sectors, while the data for 1998-2004 were calculated based on 43 industrial sectors, due to changes in environmental pollution measurement methods in China.

It was Grossman and Krueger (1995) who first introduced three effects on environmental quality change. The first is the scale effect, in which a larger economic scale means more production activity and therefore higher requirements for natural resources, resulting in more pollution emissions. The second is the composition effect, which reflects the impact of adjustments in industrial composition and changes in factor-input combinations on environmental pollution. The last is the technique effect, in which technological progress and the use of environmentally friendly technology helps to decrease pollution emissions.

Like Copeland and Taylor (2003), our empirical model also considers the three effects on pollution emissions. The scale effect is measured using regional gross domestic product $\left(g d p_{i t}\right)$, which is the real gross domestic product (GDP) after removing the effect of inflation. The composition effect is identified as the combination of factor inputs-namely, physical capital per capita, which is the ratio of physical capital $\left(k_{i t}\right)$ to labour inputs $\left(l_{i t}\right)$. It is found that capitalintensive industries can generally cause more pollution emissions than other industries; therefore, the coefficient of physical capital per capita is expected to be positive. Zhang et al. (2004) estimated the physical capital stock for China's 30 provinces by using a long period of sample data from 1952 to 2000; here we follow their method in obtaining the capital stock data. The role of human capital accumulation is also considered. As in Barro and Lee (2001), we use the average educational attainment to measure the level of human capital stock among different regions, which is the ratio of total educational attainment to the total population. Specifically, the educational attainment is specified as six years for primary school graduates, and nine, 12 and 16 years for junior middle school graduates, senior middle school graduates and university graduates respectively. The unit of human capital stock $(h c)$ is therefore educational years per capita, and we expect its coefficient to be negative, as higher human capital accumulation attracts cleaner industries to invest. Finally, similar to Antweiler et al. (2001), we use the lagged term of China's gross national product (GNP) per capita to capture the role of the technique effect, since it is acknowledged widely that a higher GNP per capita reflects a higher level of technology use. Due to data availability, here we use GDP per capita as a proxy for the technique effect. 
A number of pollution control variables are also included. The first is population density (density ${ }_{i t}$ ), which is the population per square kilometre; and, as Antweiler et al. (2001) point out, its coefficient could be negative since a higher population density causes greater marginal pollution damage. The second is environmentally related research and development expenditure $\left(r d_{i t}\right)$, which is used to measure pollution abatement endeavours, and the ratio of $r d_{i t}$ to GDP is used. Another indicator is the number of environmentally related institutions $\left(\right.$ agency $\left._{i t}\right)$. We expect that the coefficients of $r d_{i t}$ and agency $y_{i t}$ will be negative, to reflect the role of environmental regulation and pollution abatement efforts in reducing industrial emissions.

The data for the five pollutant emissions, as well as the other two control variables, $r d_{i t}$ and agency $_{i t}$, are collected from various issues of the China Environment Yearbook (SEPA, various years). Data for other indicators were collected from the China Statistical Yearbook (NBS various years). Except for $r d_{i t}$, the logarithm value of all other variables is used. For our panel data estimation method, the usual Hausman test was employed to choose fixed-effect (FE) or random-effect (RE) models. If the value of the Hausman test statistic is larger than the critical value, the null hypothesis can be rejected and fixed effects are preferred to random effects. The White cross-section method is derived by treating the panel regression as a multi-variance regression (with an equation for each cross-section), and by computing White-type robust standard errors for the system of equations. This estimator is robust for cross-equation (contemporaneous) correlations as well as different error variances in each cross-section (Wooldridge 2002). The basic statistical information is shown in Table $11.4 .^{6}$ It can be seen that significant regional disparity exists in terms not only of various pollution emissions, but in attracting foreign investment. We therefore estimate the inverted-U cure not only for our national sample data, but for controlling different regions in the next section.

\section{Estimation results}

\section{The total sample estimation result}

We first estimate the impact of foreign investment on China's pollution emissions for the total sample of 29 provinces and the results are shown in Table 11.5.

Among the five pollutant indicators we have chosen, the inverted-U curve relationship between FDI and pollution emissions is generally supported. The coefficients of $f d i_{i t}{ }^{2}$ are estimated to be significantly negative, while the coefficients of $f d i_{i t}$ are positive. Such results demonstrate that foreign investment has a non-linear impact on environmental pollution, rather than the linear one assumed in most studies. We can further calculate the threshold 


\section{Table 11.4 Basic statistical information on pollution and FDI}

\begin{tabular}{lccc}
\hline & Total sample & Coastal region & Non-coastal region \\
water & $7.21(5.57)$ & $9.24(5.91)$ & $5.78(4.85)$ \\
cod & $22.29(18.81)$ & $27.02(22.45)$ & $18.96(14.91)$ \\
gas & $56.38(43.28)$ & $64.91(50.18)$ & $50.36(36.58)$ \\
smoke & $29.62(22.04)$ & $27.35(21.64)$ & $31.22(22.21)$ \\
solid & $0.27(0.22)$ & $0.28(0.27)$ & $0.26(0.17)$ \\
FDI (US\$100 million) & $14.92(23.91)$ & $31.47(30.55)$ & $3.24(2.91)$ \\
& & & \\
\hline
\end{tabular}

Note: We list the mean value for each indictor, and the values in parentheses are the standard deviations.

Source: Authors' own calculations.

\section{Table 11.5 Total sample estimation results}

\begin{tabular}{|c|c|c|c|c|c|}
\hline & water & $\operatorname{cod}$ & gas & smoke & solid \\
\hline \multirow[t]{2}{*}{$f d i_{i t}$} & $0.538 * * *$ & $0.511^{* *}$ & $0.192 * * *$ & $0.319 * * *$ & $0.098 * *$ \\
\hline & $(6.983)$ & $(4.575)$ & $(2.691)$ & $(3.539)$ & $(2.484)$ \\
\hline \multirow[t]{2}{*}{$f d i_{i t}{ }^{2}$} & $-0.025 * * *$ & $-0.025^{* * *}$ & $-0.009 * *$ & $-0.018 * * *$ & $-0.005^{* * *}$ \\
\hline & $(-7.340)$ & $(-5.248)$ & $(-2.481)$ & $(-3.742)$ & $(-2.297)$ \\
\hline \multirow[t]{2}{*}{$g d p_{i t}$} & $0.450 * * *$ & $0.816^{* * *}$ & $0.538 * * *$ & $-0.819 * * *$ & $0.408^{* * *}$ \\
\hline & $(9.261)$ & (12.46) & $(3.366)$ & $(-4.059)$ & $(4.426)$ \\
\hline \multirow[t]{2}{*}{$(k / l)_{i t}$} & $-0.792 * * *$ & $-0.367 * * *$ & 0.023 & $0.826 * * *$ & $0.221^{* * *}$ \\
\hline & $(-16.01)$ & $(-6.169)$ & $(0.214)$ & $(6.129)$ & (3.911) \\
\hline \multirow[t]{2}{*}{$h c_{i t}$} & -0.011 & $-0.061^{*}$ & 0.042 & 0.001 & $0.079 * * *$ \\
\hline & $(-0.352)$ & $(-1.823)$ & $(0.908)$ & $(0.016)$ & (3.172) \\
\hline \multirow[t]{2}{*}{ tech $_{i t}$} & $0.509 * * *$ & $-0.233^{* * *}$ & $-0.295^{* * *}$ & 0.004 & $-0.148 * * *$ \\
\hline & (11.96) & $(-3.622)$ & $(-4.323)$ & $(0.051)$ & $(-3.471)$ \\
\hline \multirow[t]{2}{*}{ density $_{i t}$} & $0.277^{* * *}$ & $0.157^{* * *}$ & $-2.257 * * *$ & $-2.007 * * *$ & $-0.881^{* * *}$ \\
\hline & $(9.009)$ & $(4.248)$ & $(-4.221)$ & $(-2.973)$ & $(-2.608)$ \\
\hline \multirow[t]{2}{*}{$r d_{i t}$} & $-0.087 * *$ & $-0.406^{*}$ & $-0.250 * * *$ & $-0.224^{* *}$ & 0.003 \\
\hline & $(-2.521)$ & $(-2.984)$ & $(-3.072)$ & $(-2.186)$ & $(0.059)$ \\
\hline \multirow[t]{2}{*}{ agency $_{i t}$} & $0.194^{* * *}$ & 0.054 & 0.061 & -0.059 & -0.011 \\
\hline & $(4.177)$ & $(0.984)$ & $(0.826)$ & $(-0.643)$ & $(-0.262)$ \\
\hline $\operatorname{adj}-R^{2}$ & 0.876 & 0.731 & 0.958 & 0.923 & 0.964 \\
\hline$\chi^{2}$ & 216.58 & 253.05 & 188.74 & 207.60 & 192.23 \\
\hline Hausman & 31.57 & 33.97 & 40.45 & 38.86 & 44.29 \\
\hline observations & 377 & 377 & 377 & 377 & 377 \\
\hline
\end{tabular}

*** statistically significant at 1 per cent level

** statistically significant at 5 per cent level

* statistically significant at 10 per cent level

Note: $t$-statistic values are in parentheses; $\chi^{2}$-statistic is used to test whether the specific cross-section and period effects are both significant at the same time; and Hausman-test is used to specify the estimation panel model.

Source: Authors' own estimations. 
value of foreign investment according to the estimation results. Let us take industrial polluted water emissions as an example. Table 11.5 shows that the coefficients of $f d i_{i t}{ }^{2}$ and $f d i_{i t}$ are -0.025 and 0.538 respectively, which implies that the turning-point along its inverted-U curve is $f d i{ }^{*}=7.68$, meaning that if the real foreign investment for a certain region is lower than US\$768 million, increases in foreign investment will cause local pollution emissions to rise. On the other hand, if the real foreign investment is larger than this threshold value, environmental pollution will fall as new foreign firms enter the area. Comparing the real foreign investment for China's 29 provinces with such threshold value $f d i{ }^{*}$, we can reach a rough conclusion about the impact of foreign investment on local industrial polluted water emissions. The mean value of foreign investment for 18 provinces is lower than US $\$ 768$ million, among which the foreign investment in Hunan Province is US $\$ 747$ million, which is very near the turning-point along the inverted-U curve. It demonstrates that foreign investment generally causes local pollution emissions in the 18 provinces to go up, and therefore has a negative effect on local environmental quality. For the remaining 11 provinces, industrial polluted water emissions will decline with the entry of foreign investors; foreign investment in Hubei (US\$776 million) is a little larger than the threshold value.

We can further observe that even though an inverted-U curve is generally estimated, the shape of inverted-U curves for different pollutant indicators varies significantly, especially for their turning-points $\left(f d i^{*}\right) .^{7}$ Let us compare the two water pollutants, water and cod. For the estimation result for cod, the coefficients of $f d i_{i t}{ }^{2}$ and $f d i_{i t}$ are -0.025 and 0.511 respectively, and we can calculate the turning-point along its inverted-U curve, which is $f d i^{*}=\mathrm{US} \$ 334$ million-much lower than the threshold value in the industrial polluted water emission estimation. For the other three indicators, we obtain their threshold values as US $\$ 669$ million (gas), US $\$ 122$ million (smoke) and US $\$ 2.683$ billion (solid). The threshold values for different pollutant indicators determine how foreign investment affects local environmental pollution among different regions. For example, since the turning-point for the estimation of industrial solid wastes is as high as US $\$ 2.683$ billion, only five provinces have a larger mean value of foreign investment than the threshold value: Guangdong (US $\$ 11.376$ billion), Jiangsu (US $\$ 6.173$ billion), Shanghai (US $\$ 3.778$ billion), Shandong (US $\$ 3.473$ billion) and Fujian (US $\$ 3.425$ billion). These five provinces are in coastal eastern China. In comparison, as the turning-point for industrial smoke emissions is only US $\$ 122$ million, the value of foreign investment for most provinces is larger, implying that although an inverted-U curve relationship has been estimated, most provinces have been in the right part along the 
inverted-U curve. Table 11.6 compares our estimated threshold value of FDI for five pollutants with the mean of real utilised FDI among 29 provinces. It is easy to see that five provinces-Guangdong, Jiangsu, Shanghai, Shandong and Fujian-are located in the right part of the inverted-U curve for all five pollutants, while seven provinces from the western region are still located in the left part of the curve, which implies that more foreign investment in those provinces could cause pollution emissions to rise.

The effects of other pollution control variables are also shown in Table 11.5. According to Antweiler et al. (2003), scale effect and composition effect can cause pollution emissions to rise, while the technique effect leads pollution emissions to fall. Our estimations, however, demonstrate that it is not straightforward to obtain a clear-cut conclusion concerning the three effects, since the estimated coefficients of the three effects vary significantly for different pollutant indicators (Table 11.7). For instance, since capital-intensive goods can cause a higher level of pollution emissions, the coefficient of physical capital per capita is supposed to be positive, which implies that the increase in the capital/labour ratio will cause more pollution emissions. According to Table 11.5, however, while the coefficients of gas, smoke and solid are estimated to be positive, they are significantly negative for the other two indicators, water and cod. For the other control variables, environmentally related research and development expenditure shows a significantly negative effect on pollution

\section{Table 11.6 The threshold effect of FDI for five pollutants (US $\$$ billion)}

solid (2.683)

Guangdong (11.376), Jiangsu (6.173), Shanghai (3.778), Shandong (3.473), Fujian (3.425)

$$
\text { water (0.768) }
$$

Hunan (0.747)

gas $(0.669)$

Hainan (0.627), Jiangxi (0.612), Guangxi (0.610), Henan (0.503), Sichuan (0.482), Heilongjiang (0.414), Anhui (0.369)

$\operatorname{cod}(0.334)$

Jilin (0.316), Shaanxi (0.303), Shanxi (0.182)

smoke (0.122)

Neimenggu (0.121), Yunan (0.107), Xinjiang (0.075), Guizhou (0.070), Gansu (0.061), Qinghai (0.053), Ningxia (0.026)

Note: The numbers in parentheses refer to our calculated threshold values of FDI for different pollutants, or the mean of utilised FDI among different provinces during the sample period.

Source: Authors' own calculations. 
emissions, which verifies the role of the adoption of environmentally friendly new technology and technological progress. The effects are, however, estimated to be ambiguous for the two indicators-namely, the number of environmentally related institutions and population density.

\section{Sub-sample regression results}

As mentioned already, since significant regional development disparity exists among different regions in China, we further estimate the impacts of foreign investment on local pollution emissions by dividing our total sample into two sub-samples: the coastal eastern region, and the inland region. By doing this, we can compare not only the effects of foreign investment on local environmental pollution for different regions, we can examine whether the inverted-U curve still holds robustly for our sub-sample estimation.

The estimation results for the coastal eastern regions are shown in Table 11.8. First, similar to our total sample estimation results, the coefficient of $f d i_{i t}{ }^{2}$ is estimated to be significantly negative, which means that the inverted-U curve relationship between FDI and pollution emissions holds true if considering only the coastal eastern regions in the model estimation. Meanwhile, the three effects (scale, composition and technique) are also estimated to be ambiguous. Take the composition effect measured by the ratio of physical capital to labour as an example. Although its coefficient is negative for the five pollutant indicators, it doesn't show statistically significant estimates for industrial smoke pollution and solid wastes. Furthermore, it is found that the negative composition effect is larger for cod than for industrial polluted water emissions and gas. Finally, the role of the other control variables also differs from that in the total sample estimation. Take environmentally related research and development expenditure as an example. Similar to the results reported in Table 11.5, the coefficient of $r d$ is significantly negative, as reported in Table 11.8. This finding supports the role of technological progress in reducing pollution emissions. It is also found, however, that the estimated role of research and development expenditure is generally larger than that obtained using the total sample. Since most research and development activities are taking place in the coastal eastern regions, we can conclude that research and development activities play a more significant role in improving environmental quality in coastal regions than in inland regions.

We also estimate whether the effects of foreign investment on local pollution emissions for the 17 inland provinces are non-linear, and the results are shown in Table 11.9. As for the relationship between foreign investment and pollution emissions, the inverted-U curve still holds true for two indicators: industrial 


\section{Table 11.7 Estimation results of the three effects}

\begin{tabular}{|c|c|c|c|c|c|}
\hline & water & $\operatorname{cod}$ & gas & smoke & solid \\
\hline Scale effect & $+* * *$ & $+* * *$ & $+* * *$ & $+* * *$ & $+* * *$ \\
\hline Composition effect & $-* * *$ & $+* * *$ & + & $+* * *$ & $+* * *$ \\
\hline Technique effect & $+* * *$ & $-* * *$ & $-* * *$ & + & $-* * *$ \\
\hline
\end{tabular}

Note: The composition effect is measured as the ratio of physical capital to labour. ***, **, * mean that the estimated co-efficient of various effects is statistically significant at 1, 5 and 10 per cent level respectively.

Source: Authors' own summary, based on the estimation results reported in Table 11.5.

\section{Table 11.8 Estimation results for coastal eastern regions}

\begin{tabular}{|c|c|c|c|c|c|}
\hline & water & cod & gas & smoke & solid \\
\hline \multirow[t]{2}{*}{$f d i_{i t}$} & $1.264^{* *}$ & $0.694 * * *$ & $0.717 * *$ & $0.998 * * *$ & $0.326^{*}$ \\
\hline & $(2.054)$ & $(2.678)$ & $(2.492)$ & (3.562) & $(1.719)$ \\
\hline \multirow{2}{*}{$f d i_{i t}^{2}$} & $-0.054^{* *}$ & $-0.037 * * *$ & $-0.033^{* * *}$ & $-0.052 * * *$ & $-0.016^{*}$ \\
\hline & $(-2.209)$ & $(-3.695)$ & $(-2.681)$ & $(-4.471)$ & $(-1.670)$ \\
\hline \multirow{2}{*}{$g d p_{i t}$} & -0.306 & 0.613 & $0.398^{*}$ & -0.050 & $0.831 * * *$ \\
\hline & $(-1.174)$ & $(3.896)$ & $(1.924)$ & $(-0.204)$ & $(7.516)$ \\
\hline \multirow{2}{*}{$(k / l)_{i t}$} & $-0.097 * *$ & $-0.174 * *$ & $-0.093^{* * *}$ & -0.032 & -0.003 \\
\hline & $(-1.997)$ & $(-2.401)$ & $(-2.749)$ & $(-0.926)$ & $(0.828)$ \\
\hline \multirow[t]{2}{*}{$h c_{i t}$} & 0.029 & $-0.142^{*}$ & -0.005 & 0.056 & $0.103 * * *$ \\
\hline & $(0.314)$ & $(-1.782)$ & $(-0.089)$ & $(0.786)$ & $(2.926)$ \\
\hline \multirow[t]{2}{*}{ tech $_{i t}$} & $0.267^{* *}$ & $-0.512 * *$ & $-0.165^{*}$ & $0.279 *$ & $-0.148 * * *$ \\
\hline & $(2.144)$ & $(-3.718)$ & $(-1.843)$ & $(1.947)$ & $(-2.884)$ \\
\hline \multirow[t]{2}{*}{ density $_{i t}$} & $-6.289 * * *$ & $0.385^{* * *}$ & $-1.242 * * *$ & $-3.770 * * *$ & $-2.052 * * *$ \\
\hline & $(-7.204)$ & $(3.363)$ & $(-2.947)$ & $(-5.313)$ & $(-5.280)$ \\
\hline \multirow{2}{*}{$r d_{i t}$} & $-0.313^{* *}$ & $-0.504^{* *}$ & $-0.270 * * *$ & $-0.493^{* * *}$ & -0.075 \\
\hline & $(-2.032)$ & $(-2.076)$ & $(-2.801)$ & $(-5.402)$ & $(-0.883)$ \\
\hline \multirow{2}{*}{ agency $_{i t}$} & $0.454^{* * *}$ & $0.401 * * *$ & $0.201^{* *}$ & 0.102 & -0.007 \\
\hline & $(3.092)$ & $(2.675)$ & (1.993) & (1.381) & $(-0.138)$ \\
\hline$\chi^{2}$ & 201.78 & 168.24 & 159.91 & 179.57 & 213.07 \\
\hline Hausman & 36.76 & 27.40 & 31.19 & 40.77 & 35.54 \\
\hline $\operatorname{adj}-R^{2}$ & 0.936 & 0.782 & 0.932 & 0.959 & 0.921 \\
\hline observations & 156 & 156 & 156 & 156 & 156 \\
\hline
\end{tabular}

*** statistically significant at 1 per cent level

** statistically significant at 5 per cent level

* statistically significant at 10 per cent level

Note: $t$-statistic values are in parentheses; $\chi^{2}$ is used to test whether the specific cross-section and period effects are both significant at the same time; and Hausman is used to specify the estimation panel model.

Source: Authors' own estimations. 
polluted water emissions and industrial smoke emissions. The estimation results demonstrate, however, a U-curve for the other three indicators. This finding could imply that in the initial stage, foreign investment helps to reduce environmental pollution and, once certain turning-points are passed, further increases in foreign investment cause a deterioration in local environmental quality. Furthermore, the role of other variables also varies in comparison with the results reported in Tables 5 and 8 . Again, take the effect of environmentally related research and development expenditure as an example. It is found that more environmentally related research and development expenditure significantly decreases the level of pollution emissions; however, its coefficient is estimated to be insignificant for the inland provinces, while it is positive for the pollutant cod.

\section{Comparisons of estimation results among different regions}

The regional disparity on the FDI-pollution nexus can be determined by comparing the estimation results for different provinces, and the results are shown in Table 11.10.

By comparing the estimation results for the total sample and the coastal eastern regions, we find that although an inverted-U curve relationship is generally estimated to hold for all five pollutant indicators, the shape and especially the levels of the turning-point of different inverted-U curves for the two samples vary significantly. Generally speaking, although the threshold value of the industrial solid wastes curve is obviously larger in the total sample (US $\$ 2.683$ billion) than in the coastal regions (US $\$ 1.598$ billion), the threshold values in coastal regions are larger than in the total sample for the other four pollutant indicators. According to Bao et al. (2007), the threshold value of foreign investment is possibly determined by the following factors: the first is the industrial structure of foreign investment-that is, the sector into which foreign investment flows. Specifically, if more foreign firms enter the pollutionintensive sectors in the host country, the threshold value of foreign investment is expected to be higher; in other words, there is a positive relationship between the pollution intensity of foreign investment and the threshold value of $f d i$. The second factor is how FDI affects the marginal pollution damage in host countries, which depends essentially on the income levels of local residents. Generally speaking, a higher income level leads to a higher requirement for a clean environment, and hence the marginal damage caused by pollution emissions will be accordingly more severe. The third factor is the contribution of foreign investment to local economic development. Generally, with the accumulation of foreign investment, the marginal contribution of foreign firms to the local economy will fall accordingly. Therefore, to compare the threshold 


\section{Table 11.9 Estimation results for inland provinces}

\begin{tabular}{|c|c|c|c|c|c|}
\hline & water & cod & gas & smoke & solid \\
\hline \multirow[t]{2}{*}{$f d i_{i t}$} & $1.170 * * *$ & $-0.156^{*}$ & $-0.085^{*}$ & $0.247^{* *}$ & $-0.087^{* *}$ \\
\hline & (8.085) & $(-1.633)$ & $(-1.701)$ & $(2.120)$ & $(-1.949)$ \\
\hline \multirow[t]{2}{*}{$f d i_{i t}{ }^{2}$} & $-0.056^{* * *}$ & $0.009 *$ & $0.008 * *$ & $-0.012 * *$ & $0.006 * *$ \\
\hline & $(-7.356)$ & $(1.654)$ & $(2.251)$ & $(-1.980)$ & $(2.331)$ \\
\hline \multirow{2}{*}{$g d p_{i t}$} & -0.014 & $-0.912^{* * *}$ & $0.874^{* * *}$ & -0.056 & $0.410^{* * *}$ \\
\hline & $(-0.150)$ & $(-3.843)$ & $(3.307)$ & $(-0.576)$ & (5.619) \\
\hline \multirow[t]{2}{*}{$(k / l)_{i t}$} & $-0.160 * *$ & $0.140 * * *$ & $-0.061^{* *}$ & -0.067 & $0.055^{* * *}$ \\
\hline & $(-2.064)$ & $(2.936)$ & $(-2.127)$ & $(-1.011)$ & $(3.343)$ \\
\hline \multirow[t]{2}{*}{$h c_{i t}$} & -0.073 & -0.097 & 0.033 & $0.303^{* * *}$ & -0.009 \\
\hline & $(-1.321)$ & $(-0.974)$ & $(0.329)$ & $(5.067)$ & $(-0.266)$ \\
\hline \multirow[t]{2}{*}{ tech $_{i t}$} & -0.038 & 0.136 & $-0.505^{* * *}$ & $-0.499 * * *$ & $-0.124 * * *$ \\
\hline & $(-0.605)$ & $(1.364)$ & $(-4.444)$ & $(-9.239)$ & $(-3.184)$ \\
\hline \multirow[t]{2}{*}{ density $_{i t}$} & $0.253^{* * *}$ & $4.389 * * *$ & $-1.728 * *$ & -0.009 & $3.895^{* * *}$ \\
\hline & $(5.934)$ & $(2.534)$ & $(-2.409)$ & $(-0.215)$ & (5.591) \\
\hline \multirow[t]{2}{*}{$r d_{i t}$} & -0.248 & 0.004 & -0.080 & -0.165 & -0.010 \\
\hline & $(-1.286)$ & $(0.027)$ & $(-0.744)$ & $(-0.791)$ & $(-0.139)$ \\
\hline \multirow[t]{2}{*}{ agency $_{i t}$} & $0.742^{* * *}$ & 0.077 & 0.072 & $0.737^{* * *}$ & -0.064 \\
\hline & $(6.776)$ & $(0.516)$ & $(0.689)$ & $(7.259)$ & $(-0.943)$ \\
\hline$x^{2}$ & 239.03 & 188.37 & 173.69 & 214.06 & 226.51 \\
\hline Hausman & 34.65 & 37.21 & 29.06 & 32.78 & 37.93 \\
\hline $\operatorname{adj}-R^{2}$ & 0.781 & 0.901 & 0.908 & 0.916 & 0.928 \\
\hline observations & 221 & 221 & 221 & 221 & 221 \\
\hline
\end{tabular}

*** statistically significant at 1 per cent level

** statistically significant at 5 per cent level

* statistically significant at 10 per cent level

Note: $t$-statistic values are in parentheses; $\chi^{2}$ is used to test whether the specific cross-section and period effects are both significant at the same time; and Hausman is used to specify the estimation panel model.

Source: Authors' own estimations.

values of foreign investments among different regions, we need to know how foreign investments affect local environmental pollution through the above three effects. Since the income level in coastal regions is generally much higher than in the inland provinces, it holds true that the marginal pollution damage must be larger for coastal provinces. Combining the other two effects, however, our estimation results show that the threshold values for coastal provinces are unexpectedly higher. Due to data limitation, we cannot measure the industrial composition effect of foreign investment without the industrial location data for foreign investment for different provinces, which could be a topic for future research. 


\section{Table 11.10 Comparisons of the FDI-pollution nexus among different regions (US\$ million)}

\begin{tabular}{lccccc}
\hline & & & & & \\
Total sample & water & cod & gas & smoke & solid \\
& Inverted-U & Inverted-U & Inverted-U & Inverted-U & Inverted-U \\
Coastal regions & $(768)$ & $(334)$ & $(669)$ & $(122)$ & $(2,683)$ \\
& Inverted-U & Inverted-U & Inverted-U & Inverted-U & Inverted-U \\
& $(1,211)$ & $(3,966)$ & $(1,105)$ & $(181)$ & $(1,598)$ \\
Inland regions & Inverted-U & U curve & U curve & Inverted-U & U curve \\
& $(344)$ & $(58)$ & $(20)$ & $(295)$ & $(14)$ \\
& & & & & \\
\hline
\end{tabular}

Note: The figures in parentheses are the estimated threshold values for the turning-point for different shapes of the estimated curves.

Source: Authors' own summary.

We can also compare the estimation results for inland provinces with those obtained using the total sample. Specifically, although it is found that the threshold value for the inverted-U curve among inland provinces is generally smaller, most inland provinces are still located along the left side of the inverted U-curve-that is, foreign investment in those regions is still causing increased pollution emissions. Take industrial polluted water emissions as an example: the threshold value for the inland provinces is estimated to be US $\$ 344$ million-much smaller than the value for our total sample (US $\$ 1.211$ billion). We find, however, that 10 of 17 inland provinces have a mean value of foreign investment lower than the threshold value. This suggests that a significant regional disparity exists in terms of their ability to attract foreign investment. While the mean value of foreign investment for the coastal provinces is US $\$ 3.147$ billion, the mean value for the 17 inland provinces is much smaller (US $\$ 324$ million). Since most inland provinces are still in the initial stage of attracting foreign investment, a positive relationship generally occurs between foreign investment and local pollution emissions, suggesting that foreign investment has a negative effect on local environmental quality in those inland regions.

\section{Conclusions}

In this chapter, we investigate the possible non-linear impact of foreign investment on local pollution emissions in China. The hypothesis that an inverted-U curve relationship exists between foreign investment and pollution is supported empirically using the panel data for 29 Chinese provinces. The fact that an inverted $\mathrm{U}$-curve exists between foreign investment and pollution 
emissions suggests that foreign investment helps, in general, to reduce pollution emissions in China. The empirical results also show that there are significant regional disparities with respect to the impact of foreign investment on local pollution levels. More specifically, those threshold values for most of the pollutants are much higher in some of the most developed coastal regions than in those relatively less developed inland regions in China. This implies that for those more developed regions, more foreign investment inflows will contribute to further reduction of pollution levels, while further increases in foreign investment in inland provinces will continue to a worsening of their environment.

These findings do not, however, imply that the only effective way to alleviate environmental protection pressure in the early stages of developmentespecially in those less developed inland regions-is to attract more foreign investment, until a certain threshold value along the inverted-U curve is passed. In other words, it is misleading to conclude that the environmental damage caused by the entry of foreign firms in the initial stage can be remedied naturally by the continual accumulation of foreign investment. This is mainly because, as the empirical results show, most Chinese provinces have a long way to go in attracting foreign investment before they reach the turning-point along the inverted-U curve, as the real value of foreign investment in these regions is much lower than the estimated threshold value-namely, their FDI-pollution relationship is still located along the left side of the inverted-U curve. In other words, they have to continue to pay a significantly high cost of environmental degradation as a result of attracting foreign investment and economic growth. Given that China has set a target of reducing overall pollution emissions, whether these inland provinces can achieve their objectives in reducing emissions along the path of growth and development will be crucial for China to meet its targets. These inland provinces will need financial and technological support to enable them to comply with toughened government emissions regulations, similar to the way developing countries are treated in fulfilling their obligations to reduce emissions. Firms in the more developed regions in China and foreign investment can help inland provinces to fulfil their obligations.

It is also in the interest of inland regions to reduce emissions by improving environmental standards, even though pollution abatement endeavours will involve additional costs, which usually increase with pollution emissions. The costs associated with pollution damage, however, could be much higher, especially in cases where environmental damage cannot be remedied in the short term. Land erosion, deforestation, radiation pollution, the loss of species diversity and even the extinction of certain species are a few examples. These considerations require that governments regulate and monitor environmental 
pollution even in the early phase of industrialisation when environmental qualities are most compromised. Furthermore, the shape and threshold value of the turning-point of the inverted-U curve depend essentially on the industrial composition of foreign investment (Bao et al. 2007). Therefore, in order to avoid the trap of a race to the bottom, more attention should be paid to the industrial structure of foreign investment rather than to the scale of those investments. Finally, since the role of pollution control variables is incorporated in this study, the results suggest that the combination of complementary policies should also be considered in order for China to better deal with the trade-off between economic growth and environmental pollution-by implementing policies aimed at alleviating environmental pressures, such as increases in environmentally related research and development and provision of technical support.

\section{Notes}

1 For example, in 2006, the share of FDI in secondary industry was as large as 63.59 per cent; it was 2.03 per cent for electricity, gas and water production, 1.09 per cent for the building industry and 0.73 per cent for the mining industry. All four industries are commonly regarded as being pollution intensive.

2 For a review of the literature on empirical studies of the pollution haven hypothesis, see Dean et al. (2004) and Copeland and Taylor (2004).

3 For example, in their empirical studies of the relationship between foreign investment and environmental regulation and pollution emissions, the estimation results remain puzzling. While some authors - such as List and Co (2000), Keller and Levinson (2002) and Fredriksson et al. (2003)—empirically support the pollution haven hypothesis, others deny the effect of the stringency of environmental policies on the location choice of foreign firms, or the $\mathrm{PHH}$ exists only under certain conditions (for example, Levinson 1996; List et al. 2004; Henderson and Millimet 2007). A review of the literature on the PHH tests can be found in Copeland and Taylor (2004).

4 It was Grossman and Krueger (1991) who first proposed the existence of such an inverted-U curve in their study of the environmental consequences of the North American Free Trade Agreement (NAFTA). For a review of the literature on EKC studies, see Stern (1998) and Dinda (2004).

5 In one of our recent working papers (Bao et al. 2007), by introducing international capital flows into the original framework of Copeland and Taylor (2003), we provide mathematical proof of such an inverted-U curve relationship between foreign investment and pollution emissions in host countries. Additionally, as long as the environment is regarded as a normal good, this inverted-U shape conclusion is very robust—-whether foreign firms invest in pollution-intensive or clean sectors.

6 As usual, the coastal region includes 12 provinces and municipalities, such as Beijing, Tianjin and Hebei. The remaining 17 provinces all belong to the inland regions, while Chongqing is combined with Sichuan's provincial data.

7 Some authors, such as Wang and Jin (2002) and Liang (2006), empirically find a negative effect of foreign investment on pollution emissions in China. Similarly, we also estimate the linear 
effect of foreign investment on the five pollutants, and our estimation results are consistent with those authors' findings-except that the coefficient of foreign investment is insignificant for industrial solid wastes; it is significantly negative for the other four pollutants: -0.018 (water), -0.049 (cod), -0.168 (gas), -0.008 (smoke).

\section{References}

Antweiler, W., Copeland, S. and Taylor, M., 2001. 'Is free trade good for the environment?', American Economic Review, 91(4):877-908.

Bao, Q., Chen, Y. and Song, L., 2007. Foreign direct investment and pollution in host countries: a theoretical approach, Working Paper, Department of International Trade and Economics, Nankai University, Tianjin.

Barro. R. and Lee, J.-W., 2001. 'International data on educational attainment: updates and implications', Oxford Economic Papers, 53(3):541-63.

Birdsall, N. and Wheeler, D., 1993. 'Trade policy and industrial pollution in Latin America: where are the pollution havens', Journal of Environment \& Development, 2(1):137-47.

Cheung, K.-y. and Lin, P., 2004. 'Spillover effects of FDI on innovation in China', China Economic Review, 15:25-44.

Chudnovsky, D. and Lopez, A., 1999. TNCs and the diffusion of environmentally friendly technologies to developing countries, Mimeo., Copenhagen Business School Cross Border Environmental Project.

Copeland, B. and Taylor, S., 2003. Trade and the Environment, Princeton University Press, Princeton, NJ.

—_, 2004. 'Trade, growth and the environment', Journal of Economic Literature, 42(1):7-71.

Dasgupta, S., Laplante, B., Wang, H. and Wheeler, D. 2002. 'Confronting the Environmental Kuznets Curve', Journal of Economic Perspectives, 16(1): 147-168.

Dean, M., Lovely, E. and Wang, H., 2004. Foreign direct investment and pollution haven, evaluating the evidence from China, Mimeo., US International Trade Commission, Washington, DC.

Eskeland, G. and Harrison, E., 2003. 'Moving to greener pastures? Multinationals and the pollution haven hypothesis', Journal of Development Economics, 70:1-23.

Fredriksson, P., List, J. and Millimet, D., 2003. 'Bureaucratic corruption, environmental policy and inbound US FDI: theory and evidence', Journal of Public Economics, 87:1407-30.

Grossman, G. and Krueger, A., 1991. Environmental impacts of a North American Free Trade Agreement, NBER Working Papers 3914, Cambridge, Mass. 
He, J., 2002. Pollution haven hypothesis and environmental impacts of foreign direct investment: the case of industrial emission of sulfur dioxide $\left(\mathrm{SO}_{2}\right)$ in China, Working Paper, University of Auvergne, France.

Henderson, D. and Millimet, D., 2007. 'Pollution abatement costs and foreign direct investment inflows to US states: a nonparametric reassessment', Review of Economics and Statistics, 89:178-83.

Keller, W. and Levinson, A., 2002. 'Pollution abatement costs and foreign direct investment inflows to the US states', Review of Economics and Statistics, 84:691-703.

Letchumanan, R. and Kodama, F., 2000. 'Reconciling the conflict between the "pollution-haven" hypothesis and an emerging trajectory of international technology transfer', Research Policy, 29:59-79.

Levinson, A., 1996. 'Environmental regulations and manufacturers' location choices', Journal of Public Economics, 62:5-29.

Liang, F., 2006. Does foreign direct investment harm the host country's environment?, Mimeo., Hass School of Business, University of California, Berkeley.

List, J. and Co, C., 2000. 'Environmental regulations on foreign direct investment', Journal of Environmental Economics and Management, 40:1-20.

List, J., McHone, W. and Millimet, D., 2004. 'Effects of environmental regulation on foreign and domestic plant births: is there a home field advantage?', Journal of Urban Economics, 56:303-26.

National Bureau of Statistics (NBS), various years. China Statistical Yearbook, China Statistics Press, Beijing.

Smarzynska, B. and Wei, S.-J., 2001. Pollution havens and foreign direct investment: dirty secret or popular myth?, NBER Working Paper 8465.

State Environmental Protection Administration (SEPA), various years. China Environment Yearbook, China Environment Yearbook Press, Beijing.

Stern, D.I., 1998, 'Progress on the environmental Kuznets curve?', Environment and Development Economics, 3:173-96.

Wang, H. and Jin, Y., 2002. Industrial ownership and environmental performance: evidence from China, World Bank Policy Research Working Paper 2936.

Wayne, B. and Shadbegian, R., 2002. When do firms shift production across states to avoid environmental regulation?, NBER Working Papers 8705.

Wooldridge, J., 2002. Econometric Analysis of Cross Section and Panel Data, The MIT Press, Cambridge, Mass.

Yao, S., 2006. 'On economic growth, FDI and exports in China', Applied Economics, 38:339-51.

Zhang, J., Wu, G.Y. and Zhang, J.P., 2004. 'Estimation of China's provincial physical capital stock: 1952-2000', Economic Research, 10:5-44. 